\title{
Association between vitamin D deficiency and serum Homocysteine levels and its relationship with coronary artery disease
}

\author{
Monica Verdoia ${ }^{1,2}$ D $\cdot$ Matteo Nardin $^{3} \cdot$ Rocco Gioscia $^{2,4} \cdot$ Arraa Maddalena Saghir Afifeh $^{2} \cdot$ Filippo Viglione $^{2}$. \\ Federica Negro ${ }^{2} \cdot$ Marco Marcolongo $^{1}$ - Giuseppe De Luca ${ }^{2,4}$ on behalf of the Novara Atherosclerosis Study Group \\ (NAS)
}

Accepted: 10 January 2021 / Published online: 4 February 2021

(c) The Author(s), under exclusive licence to Springer Science+Business Media, LLC part of Springer Nature 2021

\begin{abstract}
Homocysteine (Hcy) elevation and vitamin D deficiency have emerged as potential markers of coronary artery disease (CAD). However, even tough hypovitaminosis D has been suggested to interfere with Hcy catabolism, no study has so far addressed the interaction of vitamin D and Hcy and their impact on CAD, that was the aim of present study. A cohort of consecutive patients undergoing coronary angiography in a single center were included and analyzed within the year 2019. Significant CAD was defined as at least 1 vessel stenosis $>50 \%$, while severe CAD as left main and/or three-vessel disease. Hcy and vitamin D levels were assesssed at admission. We included 3150 patients undergoing coronary angiography at our centre, who were divided according to the quartiles values of vitamin D. Patients with lower levels of Vitamin D displayed a higher cardiovascular risk profile and a higher prevalence of CAD. We observed an inverse linear relationship between lower levels of vitamin D and higher Hcy $(r=-0.092, p<0.001)$ and a higher prevalence of hyperhomocysteinemia in patients with lower quartiles values of vitamin $\mathrm{D}(\mathrm{p}<0.001)$. By forward conditional regression model, low vitamin $\mathrm{D}$ appeared as independent predictors of Homocysteine levels above the median $(\mathrm{OR}[95 \% \mathrm{CI}]=1.79[1.37-2.33], \mathrm{p}<0.001)$. In addition, patients with low vitamin D (below the median) and increased Hcy displayed a non-significantly higher rate of CAD ( $81 \%$ vs $77.7 \%, \mathrm{p}=0.13$, adjusted $\mathrm{OR}[95 \% \mathrm{CI}]=1.16[0.88-1.54], \mathrm{p}=0.29$ ) but a significant increase in the rate of severe left main/3vessel CAD (37.4\% vs 30.5\%, $\mathrm{p}=0.005$, adjusted $\mathrm{OR}[95 \% \mathrm{CI}]=1.29[1.02-1.67], \mathrm{p}=0.04)$. Among patients with vitamin $\mathrm{D}$ levels above the median, Hcy levels did not impact on the prevalence and extent of CAD $(77.7 \mathrm{vs} 77.2 \%, \mathrm{p}=0.81$, adjusted $\mathrm{OR}[95 \% \mathrm{CI}]=0.94[0.73-1.20], \mathrm{p}=0.60$ for $\mathrm{CAD}$ and $31.8 \%$ vs $27.7 \%, \mathrm{p}=0.08$, adjusted $\mathrm{OR}[95 \% \mathrm{CI}]=0.97[0.75-1.25]$, $\mathrm{p}=0.81$ for severe left main/3-vessel CAD). No significant interaction between Hcy and vitamin $\mathrm{D}$ with CAD or severe $\mathrm{CAD}$ was observed. The present study shows an independent inverse linear relationship between vitamin $\mathrm{D}$ and Hcy values. Moreover, the association of Hcy with the extent of CAD was significant only among patients with hypovitaminosis $\mathrm{D}$, and not in the cohort of subjects with vitamin D levels above the median, suggesting that a normal vitamin D status can prevent the deleterious effects of hyperhomocysteinemia on coronary atherosclerosis, a hypothesis that certainly needs further confirmation in larger randomized trials.
\end{abstract}

Keywords Vitamin D $\cdot$ Homocysteine $\cdot$ Coronary artery disease $\cdot$ Coronary angiography

Giuseppe De Luca

giuseppe.deluca@maggioreosp.novara.it

1 Cardiologia e Unità Coronarica, Ospedale degli Infermi, ASL Biella, Biella, Italy

2 Department of Translational Medicine, Università del Piemonte Orientale, via solaroli 17, 28100 Novara, Italy

3 Department of Internal Medicine, Ospedali Riuniti, Brescia, Italy

4 Department of Cardiology, AOU Maggiore della Carità, Novara, Italy

\section{Highlights}

- Homocysteine (Hcy) elevation and vitamin D deficiency have emerged as potential markers of coronary artery disease (CAD).

- Previos studies have associated vitamin D deficiency with metabolic disorders and the development of CAD

- No study has so far addressed the interaction of vitamin $\mathrm{D}$ and Hcy and their impact on CAD 
- We demonstrated an inverse independent relationship between vitamin D and Hcy values in over 3000 patients undergoing coronary angiography.

- The association of Hcy with the prevalence and extent of CAD was significant only among patients with lower vitamin $\mathrm{D}$, and not in the cohort of subjects with vitamin D levels above the median

\section{Introduction}

Pharmacological innovations in cardiovascular prevention have not reduced the burden of coronary artery disease (CAD), still representing the leading cause of mortality worldwide [1-3]. Therefore, great attention has been focused in the last years on the identification of new therapeutic targets, with a particular interest being addressed towards the role of biomarkers [4-6].

Homocysteine (Hcy) is an intermediate metabolite of methionine, whose elevation has been associated to prooxidating and pro-trombotic status, thus inducing endothelial dysfunction and platelet hyperreactivity, potentially enhancing the risk of stroke and cardiovascular events and favouring the progression of CAD [7-9]. However, despite the strong association of hyperhomocysteinemia with coronary atherosclerosis, the supplementation with folates for lowering the levels of Hcy has not demonstrated any benefit in the reduction of cardiovascular risk [10], suggesting the presence of additional factors potentially interfering with the metabolism of Hcy and conditioning the benefits of its reduction.

Vitamin D deficiency represents an established and diffuse cardiovascular risk factor, being involved in the pathogenesis of hypertension and diabetes mellitus and promoting the dysregulation of the inflammatory response and pro-oxidant status [11-13]. In fact, several studies have associated vitamin D deficiency with the development of CAD and with metabolic disorders, including adverse serum lipid and glycemic profiles and elevated Hcy $[14,15]$. However, whether this observation represents an independent association, or rather the mirror of concomitant comorbidities, is still a matter of debate. Moreover, no study has ever evaluated the impact of vitamin D deficiency on Hcy and their associated role on $\mathrm{CAD}$, that was therefore the aim of the present study.

\section{Methods}

We included consecutive patients undergoing coronary angiography between January 2010 and September 2016 at the Azienda Ospedaliera-Universitaria, "Maggiore della Carità", Novara, Italy. Informed consent was obtained from all patients before angiography. The protocol was approved by our local Ethical Committee and is in accordance to the Declaration of Helsinki statements. All demographic and clinical data were prospectively collected in a dedicated database. Hypertension was defined as a systolic blood pressure $(\mathrm{BP})>140 \mathrm{mmHg}$ and/or a diastolic $\mathrm{BP}>90 \mathrm{mmHg}$ or on-treatment with antihypertensive medications. The diagnosis of diabetes was based on previous history of diabetes treated with or without drugs, fasting glycaemia $>126 \mathrm{mg} / \mathrm{dl}$ or glycosylated haemoglobin $>6.5 \%$. Hypercholesterolemia was defined as previous history of hypercholesterolemia, chronic treatment with any cholesterol-lowering agent at admission, or fasting total cholesterol $>200 \mathrm{mg} / \mathrm{dl}$. No exclusion criteria were applied but for patients' refusal to sign informed consent.

\section{Biochemical measurements}

Blood samples were drawn at admission from patients undergoing elective (following a fasting period of $12 \mathrm{~h}$ ) or urgent coronary angiography for main chemistry and genetic assessment. Glucose, creatinine, uric acid levels, homocysteine, blood cells count and lipid profile were determined by standard methods, as previously described [16]. Vitamin D dosing was performed by chemiluminescence method through LIAISON ${ }^{\circledR}$ Vitamin D assay (Diasorin Inc). The normal range for 25-OH D3 levels in our laboratory is from 30 to $100 \mathrm{ng} / \mathrm{ml}$, according to literature reference [17]. Severe vitamin D deficiency was considered for levels beyond $10 \mathrm{ng} / \mathrm{ml}$ according to literature. Homocysteine levels were analysed as previously described [16]. Hyperhomocysteinemia was defined for levels above $13.9 \mathrm{nmol} / \mathrm{ml}$. (Upper Limit Normal, ULN).

\section{Coronary angiography}

Coronary angiography was routinely performed by the Judkins technique, preferring the radial approach, using 6-French right and left heart catheters. Quantitative coronary angiography was performed by an automatic edgedetection system (Siemens Acom Quantcor QCA, Erlangen, Germany). After the visual inspection of the coronary artery, the frame of optimal clarity was selected, showing lesion at maximal narrowing and arterial silhouette in sharpest focus. After the calibration of guiding catheter, the analysed arterial segment with coronary lesion was defined by moving the cursor from the proximal to the distal part of coronary artery to ensure adequate determination of reference diameter. We have measured minimal luminal diameter, reference diameter, percent diameter stenosis and length of the lesion.

Significant CAD was defined as at least 1 coronary stenosis $>50 \%$. Severe CAD was defined as 3 -vessel disease and/or left main disease. In case of patients who had previously undergone percutaneous coronary intervention, even 
though no restenosis was observed, the treated vessel was counted as significantly diseased. In previously bypassed patients, native arteries and grafts were taken into account in the evaluation of extension of artery disease (number of diseased vessels).

\section{Statistical analysis}

Statistical analysis was performed using SPSS 22.0 statistical package within the year 2019. Continuous data were expressed as mean $\pm \mathrm{SD}$ and categorical data as percentage. Analysis of variance and the chi-square test were used for continuous and categorical variables, respectively. Patients were grouped according to quartiles values of vitamin D. Linear regression analysis was used to define the relationship between homocysteine levels and vitamin D. A stepwise forward conditional multivariate logistic regression analysis was performed to assess the predictors of elevated homocysteine, whereas a multivariate logistic analysis was performed to assess the impact of Hcy on coronary artery disease, according to vitamin D levels and after correction for baseline confounding factors that were entered in the model in block. Results were considered statistically significant for a two-tailed $\mathrm{p}<0.05$.

\section{Results}

We included 3150 patients undergoing coronary angiography at our centre, that were divided according to quartiles values of vitamin $\mathrm{D}(<8.3 ; 8.3-14.59 ; 14.6-22.41 ; \geq 22.42)$.

Main clinical and demographic features of included patients and baseline chemistry profile are displayed in Table 1.

Patients with lower levels of Vitamin D were older, more often females, with larger BMI $(\mathrm{p}<0.001)$, and displayed a higher rate of diabetes mellitus $(p<0.001)$, renal failure $(p=0.01)$, active smoke $(p=0.01)$, previous history of myocardial infarction $(\mathrm{p}=0.01)$, percutaneous and surgical coronary revascularization $(\mathrm{p}<0.001$ and $\mathrm{p}=0.003$, respectively). Indication to angiography was more often an ACS in patients with lower vitamin D quartiles $(\mathrm{p}<0.001)$ and they received less frequently statins $(p<0.001)$ and ASA $(p=0.03)$ and more often diuretics $(p<0.001)$. An inverse association was found for vitamin $\mathrm{D}$ and platelet count $(p=0.02)$, white blood cells (WBC; $p<0.001)$, LDL cholesterol, glycaemia, C-reactive protein, uric acid and glycosylated haemoglobin ( $p<0.001$, respectively), whereas a direct relationship was observed for haemoglobin and HDL cholesterol $(\mathrm{p}<0.001$ and $\mathrm{p}=0.02)$.

Patients with lower quartiles values of Vitamin D displayed a higher prevalence of CAD ( $82.1 \%$ vs $77.2 \%$ vs $79 \%$ vs $75.3 \%, \mathrm{p}=0.005)$ and severe $\mathrm{CAD}(37.9 \%$ vs $30.9 \%$ vs $30.5 \%$ vs $28.3 \%, \mathrm{p}<0.001)$.

\section{Vitamin D and Hcy}

As shown in Fig. 1, we observed an inverse linear relationship between lower levels of vitamin D and higher Hcy $(\mathrm{r}=-0.092, \mathrm{p}<0.001)$.

In fact, the prevalence of hyperhomocysteinemia was increased in patients with lower quartiles values of vitamin $\mathrm{D}(\mathrm{p}<0.001$, Table 1$)$.

By forward conditional regression model, we identified male gender, advanced age, renal failure, presentation with acute coronary syndrome and the levels of haemoglobin and vitamin $\mathrm{D}$ as independent predictors of Homocysteine levels above the median $(\geq 16.2 \mathrm{nmol} / \mathrm{ml})$. The odds ratios with confidence intervals for Hcy above the median are displayed in Table 2.

\section{Hcy and CAD according to vitamin D status}

Patients were divided according to median values of vitamin $\mathrm{D}(<14.6 \mathrm{ng} / \mathrm{ml}, \mathrm{n}=1541 ; \geq 14.6 \mathrm{ng} / \mathrm{ml}, \mathrm{n}=1563)$.

In patients with lower levels of vitamin $\mathrm{D}$, Table 3 -Supplementary displays the main clinical features between patients with median values of Hcy below or above the median $(16.2 \mathrm{nmol} / \mathrm{ml})$. Patients with higher Hcy levels were older $(\mathrm{p}<0.001)$, males $(\mathrm{p}=0.001)$, with higher rate of hypertension, renal failure and previous myocardial infarction ( $\mathrm{p}<0.001, \mathrm{p}<0.001$ and $\mathrm{p}=0.02$, respectively). Hcy elevation was associated with the use of beta-blockers $(\mathrm{p}<0.001)$, nitrates, calcium antagonists $(\mathrm{p}=0.001)$ and diuretics $(p<0.001)$, lower glycaemia $(p=0.005)$ and higher creatinine and uric acid $(\mathrm{p}<0.001)$.

As shown in Fig. 2, patients with lower vitamin D and increased Hcy displayed a non-significantly higher rate of CAD $(81 \%$ vs $77.7 \%, \mathrm{p}=0.13$, OR $[95 \% \mathrm{CI}]=1.29[1.001-1.63, \mathrm{p}=0.06)$ and , as in Fig. 3-Supplementary, a significant increase in the rate of severe left main $/ 3$-vessel CAD (37.4\% vs $30.5 \%, p=0.005$, $\mathrm{OR}[95 \% \mathrm{CI}]=1.37[1.11-1.70], \mathrm{p}=0.004)$.

Angiographic features according to median Hcy levels are displayed in Table 4-Supplementary, showing a higher prevalence of lesions of the left anterior descending artery $(p=0.001)$ and lower rate of intracoronary thrombus at angiography $(\mathrm{p}=0.01)$.

At multivariate analysis, after correcting for baseline values, we confirmed the significant independent association of Hcy above the median only for Left Main/3-vessel CAD while not for overall CAD (adjusted $\mathrm{OR}[95 \% \mathrm{CI}]=1.29[1.02-1.67], \mathrm{p}=0.04$ for severe $\mathrm{CAD}$ and adjusted OR[95\% CI] $=1.16[0.88-1.54], \mathrm{p}=0.29$ for $\mathrm{CAD}$ ). 
Table 1 Clinical characteristics according to vitamin $\mathrm{D}$ quartiles

\begin{tabular}{|c|c|c|c|c|c|}
\hline Baseline clinical characteristics & $\begin{array}{l}\text { I quart } \\
(<8.3) \\
\mathrm{N}=772\end{array}$ & $\begin{array}{l}\text { II quart } \\
(8.3-14.59) \\
\mathrm{N}=769\end{array}$ & $\begin{array}{l}\text { III quart } \\
(14.6-22.41) \\
\mathrm{N}=782\end{array}$ & $\begin{array}{l}\text { IV quart } \\
(\geq 22.42) \\
\mathrm{N}=781\end{array}$ & $P$ value \\
\hline Age $($ mean $\pm \mathrm{SD})$ & $69.4 \pm 11.7$ & $67.9 \pm 11.2$ & $66.5 \pm 10.9$ & $67.7 \pm 10.7$ & $<0.001$ \\
\hline Male Sex $(\%)$ & 62 & 74.9 & 76.8 & 70.3 & $<0.001$ \\
\hline $\mathrm{BMI}($ mean $\pm \mathrm{SD})$ & $27.3 \pm 5.1$ & $27.5 \pm 4.6$ & $27.2 \pm 4.3$ & $26.5 \pm 4.3$ & $<0.001$ \\
\hline Hypercholesterolemia (\%) & 55.6 & 55.6 & 56 & 56 & 0.84 \\
\hline Diabetes mellitus (\%) & 43.8 & 35.4 & 37.4 & 31.8 & $<0.001$ \\
\hline Renal failure (\%) & 31.5 & 23.5 & 22 & 25.6 & 0.01 \\
\hline Active smokers (\%) & 28.4 & 24.6 & 19 & 15.9 & 0.01 \\
\hline Hypertension (\%) & 77.5 & 72.7 & 72.4 & 75.4 & 0.35 \\
\hline History of MI (\%) & 23.8 & 24.3 & 20.6 & 19.2 & 0.01 \\
\hline Previous PCI (\%) & 28.3 & 32.5 & 32.8 & 37.2 & $<0.001$ \\
\hline Previous CABG (\%) & 13.9 & 10.6 & 8.2 & 9.8 & 0.003 \\
\hline Hyperhomocysteinemia (\%) & 72.1 & 68.5 & 66.5 & 63.9 & $<0.001$ \\
\hline Indication to angiography & & & & & $<0.001$ \\
\hline Stable angina/silent ischemia (\%) & 20.1 & 28.2 & 31.9 & 38.6 & \\
\hline STEMI/ACS (\%) & 56.9 & 54.7 & 51.8 & 44 & \\
\hline $\begin{array}{l}\text { Cardiomyopathy/valvular dis- } \\
\text { ease/arrhythmias (\%) }\end{array}$ & 23 & 17.2 & 16.3 & 17.4 & \\
\hline \multicolumn{6}{|l|}{ Concomitant medications } \\
\hline ACE inhibitors (\%) & 37.1 & 36.5 & 31.5 & 35.3 & 0.19 \\
\hline $\operatorname{ARB}(\%)$ & 23.2 & 20.6 & 23.1 & 27.3 & 0.08 \\
\hline Beta blockers (\%) & 53.9 & 53.7 & 56 & 61.4 & 0.08 \\
\hline Nitrates $(\%)$ & 30.5 & 31.8 & 34 & 35.8 & 0.37 \\
\hline Statins $(\%)$ & 45.5 & 48.9 & 53.3 & 57.9 & $<0.001$ \\
\hline ASA $(\%)$ & 56 & 57.4 & 60.2 & 64.7 & 0.03 \\
\hline Clopidogrel (\%) & 17 & 17 & 17.6 & 22.4 & 0.14 \\
\hline Calcium antagonists (\%) & 20.6 & 19.8 & 22.5 & 19.7 & 0.74 \\
\hline Diuretics (\%) & 40.3 & 31.7 & 27.9 & 29.6 & $<0.001$ \\
\hline \multicolumn{6}{|l|}{ Biochemistry parameters } \\
\hline Platelets $\left(10^{6} / \mathrm{ml} ;\right.$ mean \pm SD $)$ & $230.4 \pm 80.5$ & $223.1 \pm 64.6$ & $222.6 \pm 64.4$ & $219.8 \pm 66.7$ & 0.02 \\
\hline Haemoglobin (g/dL) & $13.1 \pm 1.9$ & $13.4 \pm 1.8$ & $13.5 \pm 1.7$ & $13.4 \pm 1.7$ & $<0.001$ \\
\hline $\mathrm{WBC}\left(10^{3} / \mathrm{ml} ;\right.$ mean $\left.\pm \mathrm{SD}\right)$ & $8.7 \pm 3.1$ & $8.2 \pm 2.7$ & $8.1 \pm 2.8$ & $7.5 \pm 2.3$ & $<0.001$ \\
\hline HDL cholesterol (mg/dL) & $42 \pm 13.6$ & $42.9 \pm 13.1$ & $43.6 \pm 13.5$ & $44.1 \pm 13.2$ & 0.02 \\
\hline LDL cholesterol (mg/dl) & $98 \pm 37$ & $96.3 \pm 35.6$ & $94.4 \pm 37.4$ & $88 \pm 31.2$ & $<0.001$ \\
\hline Glycaemia (mg/dL) & $129.6 \pm 55.3$ & $122.6 \pm 53.1$ & $121.8 \pm 43.7$ & $116.3 \pm 35.6$ & $<0.001$ \\
\hline Glycosylated haemoglobin (\%) & $6.5 \pm 1.5$ & $6.2 \pm 1.2$ & $6.2 \pm 1.2$ & $6 \pm 1$ & $<0.001$ \\
\hline Creatinine (mg/dL) & $1.03 \pm 0.51$ & $1.04 \pm 0.71$ & $1.01 \pm 0.51$ & $1.04 \pm 0.63$ & 0.66 \\
\hline $\mathrm{C}$ reactive protein $(\mathrm{mg} / \mathrm{dL})$ & $1.5 \pm 2.9$ & $1.1 \pm 2.3$ & $0.9 \pm 2.1$ & $0.98 \pm 2.3$ & $<0.001$ \\
\hline Uric acid (mg/dL) & $6.3 \pm 2.1$ & $6.2 \pm 1.9$ & $5.9 \pm 1.7$ & $5.8 \pm 1.8$ & $<0.001$ \\
\hline
\end{tabular}

$C A D$ Coronary Artery Disease, MI Myocardial Infarction, PCI Percutaneous Coronary Interventions, $C A B G$ Coronary Artery Bypass Grafting; STEMI ST-Elevation Myocardial Infarction, ACS Acute Coronary Syndrome, $C M D$ Dilated Cardiomyopathy, $L V$ Left Ventricle, $A C E$ Angiotensin Converting Enzyme, $A R B$ Angiotensin Receptor Blockers
Among patients with vitamin D levels above the median, as shown in Table 5-Supplementary, elevated Hcy (above $16.2 \mathrm{nmol} / \mathrm{ml})$ was associated to more advanced age $(\mathrm{p}<0.001)$, male sex $(\mathrm{p}=0.01)$, renal failure $(\mathrm{p}<0.001)$, hypertension $(p=0.02)$, previous MI $(p=0.03)$ and ACS at presentation $(p=0.01)$, a more frequent treatment with
ARBs $(\mathrm{p}=0.005)$, nitrates and beta-blockers $(\mathrm{p}=0.02)$, ASA $(\mathrm{p}=0.05)$ and diuretics $(\mathrm{p}<0.001)$. C-reactive protein, creatinine and uric acid levels were higher in patients with Hcy above the median ( $\mathrm{p}=0.006$ and $\mathrm{p}<0.001$, respectively).

As shown in Fig. 2, patients with vitamin D above the median displayed a similar rate of CAD (77.7 vs $77.2 \%$, 


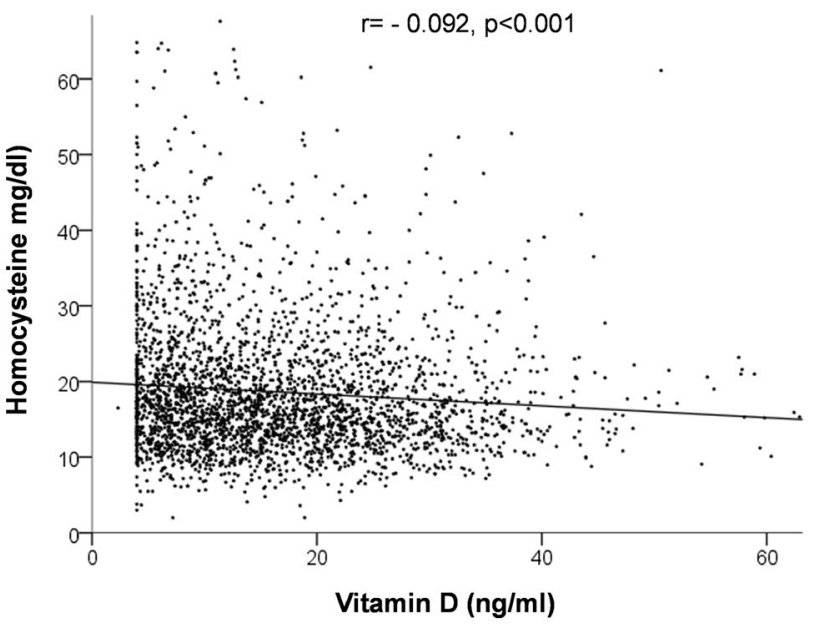

Fig. 1 Linear relationship between vitamin D levels and Homocysteine (Hcy)

Table 2 Clinical predictors of Homocysteine above the median $(\mathrm{Hcy} \geq 16.2)$

\begin{tabular}{llll}
\hline Variable & Adjusted OR & CI & P value \\
\hline Hcy above median & & & \\
Male gender & 1.67 & $1.34-2.05$ & $<0.001$ \\
Age & 1.02 & $1.02-1.04$ & $<0.001$ \\
Renal failure & 4.59 & $3.6-5.89$ & $<0.001$ \\
Hemoglobin & 1.1 & $1.04-1.17$ & $<0.001$ \\
Acute coronary syndrome & 0.67 & $0.56-0.81$ & $<0.001$ \\
Vitamin D (Ist vs II-IV) & 1.79 & $1.37-2.33$ & $<0.001$ \\
\hline
\end{tabular}

$\mathrm{p}=0.81$, OR $[95 \% \mathrm{CI}]=1.01[0.80-1.29], \mathrm{p}=0.91)$ and, as shown in Fig. 3, of severe left main/3-vessel CAD $(31.8 \%$ vs $27.7 \%, p=0.08$, OR $[95 \% \mathrm{CI}]=1.18[0.95-1.47]$, $\mathrm{p}=0.13$ ), independently from Hcy levels.

Angiographic features according to Hcy median are displayed in Table 6 , showing a higher prevalence of lesions on the left anterior descending artery $(p=0.008)$ and calcifications $(p=0.01)$ and lower rate of intracoronary thrombus and TIMI flow $<3$ at angiography $(\mathrm{p}=0.04$ and $\mathrm{p}=0.01$, respectively).

At multivariate analysis among patients vitamin $\mathrm{D}$ above the median, after correcting for baseline values, we confirmed the lack of an independent association of elevated Hcy (above the median) with overall CAD and Left Main/3-vessel CAD (adjusted $\mathrm{OR}[95 \% \mathrm{CI}]=0.94[0.73-1.20], \mathrm{p}=0.60$ and adjusted OR $[95 \% \mathrm{CI}]=0.97[0.75-1.25], \mathrm{p}=0.81$, respectively).

No significant interaction between Hcy levels and vitamin D was observed for CAD $(p=0.73)$ or severe CAD $(\mathrm{p}=0.78)$.
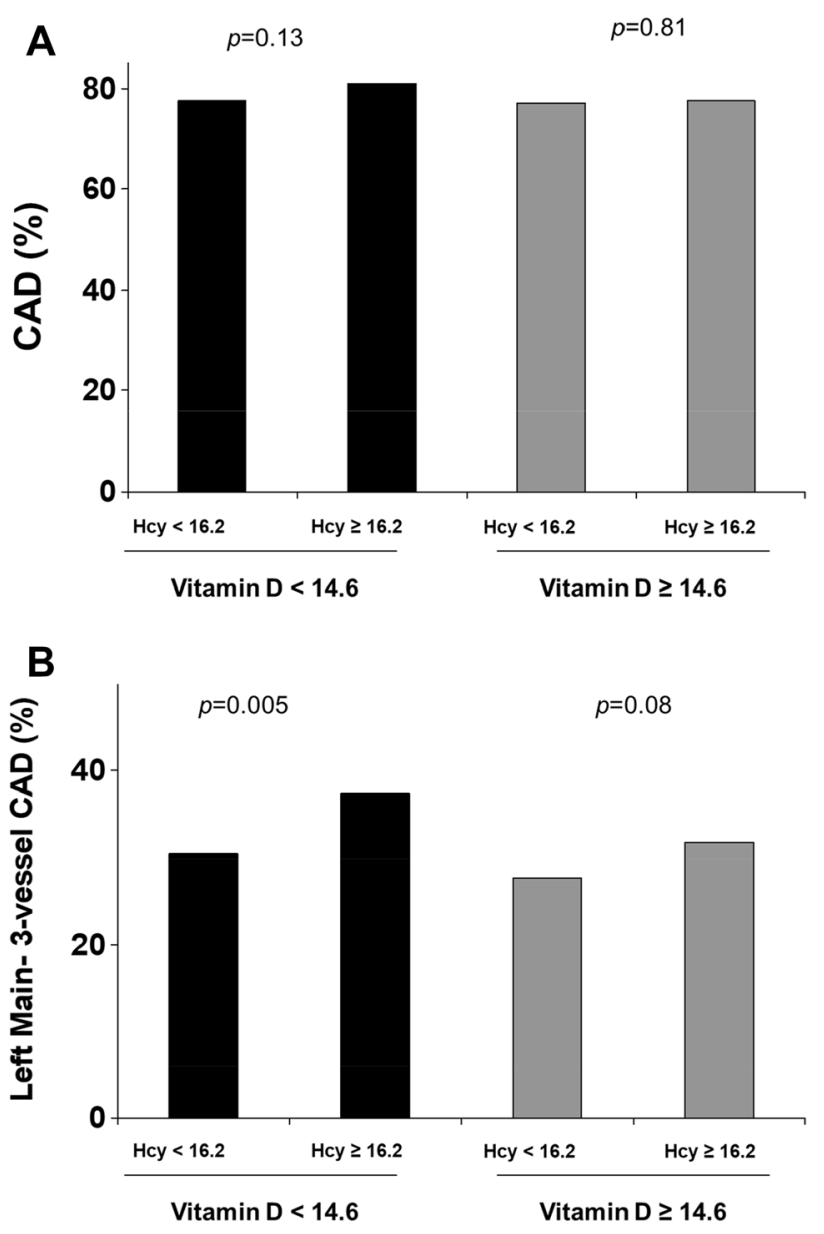

Fig. 2 Bar graph showing the prevalence of coronary artery disease (a) and severe left main/3-vessel coronary artery disease (b) according to median values of Homocysteine $(\mathrm{Hcy}<$ or $\geq 16.2 \mathrm{nmol} / \mathrm{L}$ ) in patients with vitamin $\mathrm{D}$ levels below and above the median $(<$ or $\geq 14.6 \mathrm{mg} / \mathrm{dl})$

\section{Discussion}

The present study represents the first attempt to define the relationship between vitamin D levels and Hcy and their impact on CAD in a large single centre cohort of patients undergoing coronary angiography.

We demonstrated an inverse independent relationship between vitamin D and Hcy values. Moreover, the association of Hcy with the prevalence and extent of CAD was significant only among patients with lower vitamin $\mathrm{D}$, and not in the cohort of subjects with vitamin D levels above the median.

Great efforts have been accomplished in recent years in order to reduce the burden of cardiovascular disease and spread preventive measures in general population [18-20]. However, despite the improvements in the management of patients with acute myocardial infarction, the diagnosis of CAD is generally accomplished only after a first acute 
cardiovascular event [21], therefore still establishing CAD as the leading cause of mortality worldwide (1). Thus, raising attention has been addressed towards the identification of those early markers of atherosclerosis, that could allow a better stratification of cardiovascular risk [22, 23].

Special attention has been dedicated to inflammatory biomarkers, with contrasting results [24]. Indeed, inflammation plays a central role in the pathogenesis of atherosclerosis and an elevation of inflammatory markers can mirror the activation of these processes of vascular damage [25]. However, while several humoral indicators of acute response and endothelial dysfunction have failed to demonstrate a predictive role in CAD [26], more promising results have emerged with homocysteine, an intermediate metabolite of methionine, whose plasmatic concentration may be influenced by environmental and genetic factors. Hyperhomocysteinemia, however, is a quite common condition, mainly related to chronic kidney disease, due to impaired renal escretion of homocysteine metabolites. Moreover, an important association has been described with older age and inflammatory disorders [8, 27, 28].

Hyperhomocysteinaemia has been associated to endothelial dysfunction, enhanced platelet function and pro-thrombotic status, involving several mechanisms as increased oxidative stress, and unbalance among clotting factors, thus potentially enhancing the risk of stroke and cardiovascular events [7, 29, 30]. In fact, previous studies reported that even mild homocysteine elevation could increase cardiovascular risk, [31] with Wald et al. [8] reporting a rise in relative risk by $32 \%$ every $5 \mu \mathrm{mol} / \mathrm{L}$ of Hcy elevation. In fact, Schaffer et al. [16] documented in a large cohort of patients, the independent association of Hcy elevation with angiographic findings in terms of prevalence and extent of CAD. Moreover, Hcy has been potentially involved in the development of restenosis after percutaneous coronary revascularization, although such findings were not confirmed in subsequent studies [32, 33].

However, Hcy lowering, by supplementation with folates and vitamin B12 has not provided the expected benefits in cardiovascular prevention [10,34]. Indeed, due to the multifactorial pathogenesis of hyperhomocysteinemia, additional factors have been suggested to modulate the levels of Hcy and their cardiovascular impact.

In particular, Vitamin D levels have been associated to cardiovascular risk, as hypovitaminosis D has been involved in the pathogenesis of hypertension, diabetes and in the modulation of inflammatory processes, therefore potentially conditioning the development of atherosclerosis and acute cardiovascular events $[12,13]$. In addition, vitamin D has been displayed to act as a co-factor in the metabolism of homocysteine, by the direct regulation of the levels of cystathionine $\beta$-synthase, an enzyme involved in a second pathway of degradation of Hcy, differing from the commonly addressed remethylation to methionine, that is instead controlled by folates [35].

In fact, in the large National Health and Nutrition Examination Survey (NHANES) the authors found a significant inverse association between vitamin D status and serum homocysteine concentrations [36], although this relationship was more evident among patients with vitamin D deficiency. Similar findings were obtained by Pham et al. [37], among 4475 participants involved in a primary prevention programme in Canada. However, in this population, the association of vitamin D and Hcy was significant also among patients with vitamin D levels above $50 \mathrm{nmol} / \mathrm{L}$, and a decrease in Hcy was observed in those patients whose levels of vitamin D raised during the follow-up period, suggesting that improvements in the levels of vitamin D could favour the correction of hyperhomocysteinemia.

Opposite results, instead, were achieved by García-Bailo et al. [38] in about 1900 subjects enrolled in the Canadian Health Measures Survey, where vitamin D levels related with several cardiometabolic risk biomarkers, involved in glucose metabolism and lipid profile, but not with Hcy. However, these contrasting data were achieved in "healthy" subjects, whereas no study has so far addressed the potential interaction of vitamin D and Hcy and their impact on CAD, that was, therefore, the aim of the present study.

In a large cohort of patients undergoing coronary angiography, we observed an inverse linear relationship between Hcy and vitamin D levels, with lower vitamin D quartiles being confirmed as an independent predictor of increased Hcy levels.

Patients with hyperhomocysteinemia and hypovitaminosis D displayed a higher prevalence of CAD. After dividing our population according to median values of vitamin $\mathrm{D}$, the association of Hcy elevation with CAD extent was significant only among patients with vitamin D deficiency.

A similar conclusion was reached by Esteghamati et al. [39] in a cohort of more than 4000 patients, where they documented that, among obese patients with metabolic syndrome, lower vitamin D levels were associated with an "unhealthy status" and a worse cardiometabolic profile, increased homocysteine, elevated liver enzymes and inflammatory markers.

In addition, Mao et al. [15] reported among more than 9000 patients, a significant correlation between Hcy, vitamin $\mathrm{D}$ and folates among patients with a history of cardiovascular disease, hypertension or diabetes, and especially in advanced age, suggesting that the role of both B and D vitamins supplementations should be overlooked in patients with a high cardiovascular risk profile.

In fact, the present data suggest that a normal vitamin $\mathrm{D}$ status can prevent the negative effects of hyperhomocysteinemia on coronary atherosclerosis. 
However, despite the positive impact of vitamin D supplementation on mortality and health status, contrasting findings have been reported so far on the cardiovascular benefits of the treatment with vitamin D [40, 41]. Indeed, promising results have come from the large RECORD trial [42], where treatment with vitamin D could reduce the rate of heart failure among more than 5000 elderly patients, although randomized studies on the topic are still ongoing. Therefore, future large scale trials are certainly needed to better define the pathophysiological basis of vitamin D and homocysteine interaction and to confirm the potential outcome benefits of the use of vitamin $\mathrm{D}$ in order to condition homocysteine levels and to prevent the development of CAD and thrombotic events, and especially in vue of the suggested association between COVID-19 prognosis and these biomarkers, whose pathogenetic effects are strictly linked to a pro-thrombotic milieu [43, 44].

\section{Limitations}

A first limitation of our study is represented by the cohort design of our study, therefore enrolling a heterogeneous population of high-cardiovascular risk patients. However, despite the interaction of vitamin D and Hcy had already been suggested in large cohorts of "healthy" subjects [39], our analysis represents the first exploratory study to assess this relationship among patients with already developed CAD, further confirming this association. Therefore, no pre-analytical planning could be performed.

In addition, we did not include a control healthy group in our study as this strategy would have raised some issues: as coronary angiography still represents the gold standard technique to evaluate the presence and extent of CAD, such exam could not have been performed in healthy subjects. In fact, the absence of symptoms would not have excluded with certainty the absence of coronary atherosclerosis, especially among elderly and diabetic patients, that represented the majority of our population. By the inclusion of a prospective consecutive cohort of patients undergoing coronary angiography, we could certainly overcome the potential bias due to patients' selection, when they are retrospectively identified.

Moreover, we did not perform a systematic follow-up of our patients, therefore we could not evaluate the variations of Hcy and vitamin D levels on the progression of CAD and on the occurrence of major cardiovascular events, especially among patients undergoing PCI.

Finally, we did not evaluate the levels of folates or vitamin B12 in our population, and neither the potential impact of their supplementation. Therefore we could not evaluate the potential interaction of these vitamins with vitamin D, Hcy and coronary disease.

\section{Conclusion}

The present study represents the first attempt to evaluate the interaction of vitamin D and homocysteine with the prevalence and extent of angiographically defined coronary artery disease.

We observed an independent inverse linear relationship between vitamin D and Hcy values. Moreover, the association of Hcy with the prevalence and extent of CAD was significant only among patients with hypovitaminosis $\mathrm{D}$, but not in the cohort of subjects with vitamin D levels above the median, suggesting that higher vitamin D levels can prevent the negative effects of hyperhomocysteinemia on coronary atherosclerosis. However, more definite results on the indications to vitamin $\mathrm{D}$ supplementation in $\mathrm{CAD}$ will certainly be warranted by ongoing trials.

Supplementary Information The online version of this article (https:// doi.org/10.1007/s11239-021-02391-w) contains supplementary material, which is available to authorized users.

\section{Compliance with ethical standards}

Conflict of interest No conflict of interest to disclose.

\section{References}

1. Finegold JA, Asaria P, Francis DP (2013) Mortality from ischaemic heart disease by country, region, and age: statistics from World Health Organisation and United Nations. Int J Cardiol 168(2):934-945

2. De Luca G, Suryapranata H, Stone GW, Antoniucci D, Tcheng JE, Neumann FJ, Bonizzoni E, Topol EJ, Chiariello M (2006) Relationship between patient's risk profile and benefits in mortality from adjunctive abciximab to mechanical revascularization for ST-segment elevation myocardial infarction: a metaregression analysis of randomized trials. J Am Coll Cardiol 47:685-686

3. De Luca G, Suryapranata H (2015) Recent advances in optimal adjunctive antithrombotic therapy in STEMI patients undergoing primary angioplasty: an overview. Curr Vase Pharmacol 13(5):594-615

4. Cooney MT, Dudina AL, Graham IM (2009) Value and limitations of existing scores for the assessment of cardiovascular risk: a review for clinicians. J Am Coll Cardiol 54(14):1209-1227

5. Omland T, White HD (2017) State of the art: blood biomarkers for risk stratification in patients with stable ischemic heart disease. Clin Chem 63(1):165-176

6. De Luca G, Secco GG, Santagostino M, Venegoni L, Iorio S, Cassetti E, Verdoia M, Coppo L, Di Mario C, Bellomo G, Marino P, Novara Atherosclerosis Study Group (NAS) (2012) Uric acid does not affect the prevalence and extent of coronary artery disease Results from a prospective study. Nutr Metab Cardiovasc Dis 22(5):426-433

7. Lentz SR (2005) Mechanism of homocysteine- induced atherothrombosis. J Thromb Haemost 3:1646-1654 
8. Wald DS, Law M, Morris JK (2002) Homocysteine and cardiovascular disease: evidence on casuality from a meta-analysis. BMJ 325:1202-1206

9. Marcucci R, Brogi D, Sofi F, Giglioli C, Valente S, Liotta AA, Lenti M, Gori AM, Prisco D, Abbate R, Gensini GF (2006) PAI-1 and homocysteine, but not lipoprotein (a) and thrombophilic polymorphisms, are independently associated with the occurrence of major adverse cardiac events after successful coronary stenting. Heart 92(3):377-381

10. Lange H, Suryapranata H, De Luca G, Börner C, Dille J, Kallmayer K, Pasalary MN, Scherer E, Dambrink JH (2004) Folate therapy and in-stent restenosis after coronary stenting. N Engl J Med 350(26):2673-2681

11. Rosen CJ, Adams JS, Bikle DD, Black DM, Demay MD, Manson JE, Murad M, Kovacs CS (2011) The nonskeletal effects of vitamin D: an Endocrine Society Scientific statement. Endocr Rev 33:456-492

12. Lavie CJ, DiNicolantonio JJ, Milani RV, O'Keefe JH (2013) Vitamin D and cardiovascular health. Circulation 128:2404-2406

13. Verdoia M, Schaffer A, Sartori C, Barbieri L, Cassetti E, Marino P, Galasso G, De Luca G (2014) Vitamin D deficiency is independently associated with the extent of coronary artery disease. Eur J Clin Invest 44(7):634-642

14. Glueck CJ, Jetty V, Rothschild M, Duhon G, Shah P, Prince M, Lee K, Goldenberg M, Kumar A, Goldenberg N, Wang P (2016) Associations between serum 25-hydroxyvitamin D and lipids, lipoprotein cholesterols, and homocysteine. N Am J Med Sci 8(7):284-290

15. Mao X, Xing X, Xu R, Gong Q, He Y, Li S, Wang H, Liu C, Ding X, Na R, Liu Z, Qu Y (2016) Folic acid and vitamins D and B12 correlate with homocysteine in Chinese patients with Type-2 diabetes mellitus, hypertension, or cardiovascular disease. Medicine (Baltimore) 95(6):e2652

16. Schaffer A, Verdoia M, Cassetti E, Marino P, Suryapranata H, De Luca G, Novara Atherosclerosis Study Group (NAS) (2014) Relationship between homocysteine and coronary artery disease Results from a large prospective cohort study. Thromb Res. 134(2):288-293

17. Holick MF (2007) Vitamin D deficiency. N Engl J Med 357:266-281

18. De Luca G, Cassetti E, Marino P et al (2009) Percutaneous coronary intervention-related time delay, patient's risk profile, and survival benefits of primary angioplasty vs lytic therapy in ST-segment elevation myocardial infarction. Am J Emerg Med 27(6):712-719

19. Verdoia M, Schaffer A, Suryapranata H, De Luca G (2015) Effects of HDL-modifiers on cardiovascular outcomes: a meta-analysis of randomized trials. Nutr Metab Cardiovasc Dis 25:9-23

20. Morrow DA (2010) Cardiovascular risk prediction in patients with stable and unstable coronary heart disease. Circulation 121:2681-2691

21. Karmali KN, Persell SD, Perel P, Lloyd-Jones DM, Berendsen MA, Huffman MD (2017) Risk scoring for the primary prevention of cardiovascular disease. Cochrane Database Syst Rev. 3:CD006887

22. Barbieri L, Verdoia M, Schaffer A, Marino P, Suryapranata H, De Luca G, Novara Atherosclerosis Study Group (NAS) (2015) Impact of sex on uric acid levels and its relationship with the extent of coronary artery disease: a single-centre study. Atherosclerosis 241:241-248

23. De Luca G, Verdoia M, Cassetti E, Schaffer A, Cavallino C, Bolzani V, Marino P, Novara Atherosclerosis Study Group (NAS) (2011) High fibrinogen level is an independent predictor of presence and extent of coronary artery disease among Italian population. J Thromb Thrombol 31:458-463
24. Rasouli M, Kiasari AM, Bagheri B (2007) Total and differential leukocytes counts, but not hsCRP, ESR, and five fractioned serum proteins have significant potency to predict stable coronary artery disease. Clin Chim Acta 377:127-132

25. Wildman RP, Muntner P, Chen J, Sutton-Tyrrell K, He J (2005) Relation of inflammation to peripheral arterial disease in the national health and nutrition examination survey, 1999-2002. Am J Cardiol 96:1579-1583

26. Sugiyama S, Koga H, Sugamura K, Ohba K, Matsuzawa Y, Sumida $\mathrm{H}$ et al (2009) Significance of a multiple biomarkers strategy including endothelial dysfunction to improve risk stratification for cardiovascular events in patients at high risk for coronary heart disease. J Am Coll Cardiol 54:601-608

27. Ueland PM, Nygard O, Vollset SE, Refsum H (2001) The Hordaland Homocysteine studies. Lipids 36(Suppl):S33-39

28. Bostom AG, Lathrop L (1997) Hyperhomocysteinemia in end stage renal disease: prevalence, etiology and potential relationship to atherosclerotic outcomes. Kidney Int 52:10-20

29. Fryer RH, Wilson BD, Gubler DB, Fitzgerald LA, Rodgers GM (1993) Homocysteine, a risk factor for premature vascular disease and thrombosis, induces tissue factor activity in endothelial cells. Arterioscler Thromb 13:1327-1332

30. Nygard O, Nordrehaug JE, Refsum H, Ueland PM, Farstad M (1997) Vollset SE Plasma homocysteine levels and mortality in patients with coronary artery disease. N Engl J Med 337:230-236

31. Ganguly P, Alam SF (2015) Role of homocysteine in the development of cardiovascular disease. Nutr J 14:6

32. De Luca G, Suryapranata H, Gregorio G, Lange H, Chiariello M (2005) Homocysteine and its effects on in-stent restenosis. Circulation 112:e307-e311

33. Morita H, Kurihara H, Kuwaki T, Hamada C, Kitaoka M, Suzuki S et al (2000) Homocysteine as a risk factor for restenosis after coronary angioplasty. Thromb Haemost 84:27-31

34. Li WF, Zhang DD, Xia JT, Wen SF, Guo J, Li ZC (2014) The association between $\mathrm{B}$ vitamins supplementation and adverse cardiovascular events: a meta-analysis. Int J Clin Exp Med 7(8):1923-1930

35. Kriebitzsch C, Verlinden L, Eelen G, van Schoor NM, Swart K, Lips P et al (2011) 1,25-dihydroxyvitamin D3 influences cellular homocysteine levels in murine preosteoblastic MC3T3-E1 cells by direct regulation of cystathionine beta-synthase. J Bone Miner Res 26:2991-3000

36. Amer M, Qayyum R (2014) The relationship between 25-hydroxyvitamin D and homocysteine in asymptomatic adults. J Clin Endocrinol Metab 99:633-638

37. Pham TM, Ekwaru JP, Setayeshgar S, Veugelers PJ (2015) The effect of changing serum 25-hydroxyvitamin D concentrations on metabolic syndrome: a longitudinal analysis of participants of a Preventive Health Program. Nutrients 7:7271-7284

38. García-Bailo B, Da Costa LA, Arora P, Karmali M, El-Sohemy A, Badawi A (2013) Plasma vitamin D and biomarkers of cardiometabolic disease risk in adult Canadians, 2007-2009. Prev Chronic Dis 10:E91

39. Esteghamati A, Aryan Z, Esteghamati A, Nakhjavani M (2014) Differences in vitamin D concentration between metabolically healthy and unhealthy obese adults: associations with inflammatory and cardiometabolic markers in 4391 subjects. Diabetes Metab 40(5):347-355

40. Scragg R, Stewart AW, Waayer D, Lawes CM, Toop L, Sluyter J, Murphy J, Khaw KT, Camargo CA Jr (2017) Effect of monthly high-dose vitamin D supplementation on cardiovascular disease in the vitamin $\mathrm{D}$ assessment study : a randomized clinical trial. JAMA Cardiol

41. Elamin MB, Abu Elnour NO, Elamin KB, Fatourechi MM, Alkatib AA, Almandoz JP, Liu H, Lane MA, Mullan RJ, Hazem A, Erwin PJ, Hensrud DD, Murad MH, Montori VM (2011) Vitamin 
D and cardiovascular outcomes: a systematic review and metaanalysis. J Clin Endocrinol Metab 96(7):1931-1942

42. Ford JA, MacLennan GS, Avenell A, Bolland M, Grey A, Witham M, RECORD Trial Group (2014) Cardiovascular disease and vitamin D supplementation: trial analysis, systematic review, and meta-analysis. Am J Clin Nutr. 100(3):746-755

43. Verdoia M, De Luca G (2020) Potential role of hypovitaminosis D and vitamin D supplementation during COVID-19 pandemic. QJM. https://doi.org/10.1093/qjmed/hcaa234

44. Yang Z, Shi J, He Z, Lü Y, Xu Q, Ye C, Chen S, Tang B, Yin K, Lu Y, Chen X (2020) Predictors for imaging progression on chest
CT from coronavirus disease 2019 (COVID-19) patients. Aging (Albany NY) 12(7):6037-6048. https://doi.org/10.18632/aging .102999

Publisher's Note Springer Nature remains neutral with regard to jurisdictional claims in published maps and institutional affiliations. 